\title{
Reconstruction of the Distal Oblique Bundle of the Interosseous Membrane with Extensor Carpi Radialis Hemitendon: A New Minimally-Invasive Technique
}

\section{Recostrucción de la banda oblicua distal del carpo con extensor de muñeca: Una nueva técnica mínimamente invasiva}

Francisco Martínez-Martínez ${ }^{1} \quad$ Alberto Giménez-Ros ${ }^{2}$ Vicente J. León-Muñoz ${ }^{1}$

Fernando Santonja-Medina ${ }^{1}$

${ }^{1}$ Department of Orthopedic Surgery, Hospital Clínico Universitario
Virgen de la Arrixaca, Murcia, Spain
2 Department of Orthopedic Surgery, Hospital Universitario Virgen
del Castillo de Yecla, Murcia, Spain

\begin{abstract}
Address for correspondence Francisco Martínez-Martínez, Servicio de Traumatología y Cirugía Ortopédica, Hospital Universitario Virgen de la Arrixaca, Ctra. Madrid-Cartagena s/n, 30120, El Palmar, Murcia, Spain (e-mail: fmtnez@gmail.com).
\end{abstract}

Rev Iberam Cir Mano 2020;48:138-142.

\begin{abstract}
The main stabilizing element of the distal radioulnar joint (DRUJ) is the triangular fibrocartilage complex (TFCC). Secondary stabilizers include the distal oblique band Keywords

- distal radioulnar joint

- instability

- distal oblique bundle

- reconstruction

Resumen

Palabras clave

- articulación radiocubital distal

- inestabilidad

- banda oblicua distal

- reconstrucción (DOB), which is inconsistently found. When TFCC repair has failed or cannot be performed, DOB reconstruction is a therapeutic option. Even though distal radioulnar ligamentoplasty remains the technique of choice, recent papers show similar outcomes from both methods. We present two cases of successful DOB repair with the extensor carpi radialis longus (ECRL) hemitendon.

El principal elemento estabilizador de la articulación radiocubital distal (ARCD) es el complejo fibrocartílago triangular (CFCT), y existen además estabilizadores secundarios, entre los que se encuentra de forma inconstante la banda oblicua distal (BOD). Cuando la reparación del CFCT ha fallado o no es posible realizarla, la reconstrucción de la BOD es una opción terapéutica; aunque la ligamentoplastia radiocubital distal sigue siendo la técnica de elección, están apareciendo artículos que manifiestan resultados similares entre ambas técnicas. Presentamos dos casos de reparación de BOD con hemitendón del extensor radial largo del carpo (ERLC) con buenos resultados.
\end{abstract}

\section{Introduction}

Instability of the distal radioulnar joint (DRUJ) is one of the major unsolved problems in hand surgery. Throughout history, numerous techniques have been described to increase stability and relieve pain. These techniques have ranged from repair of the triangular fibrocartilage complex (TFCC) to salvage procedures, such as Darrach, Sauvé-Kapandji, or arthroplasties in subjects with degenerative alterations. ${ }^{1}$

Anatomically speaking, this is a very complex joint, which is stabilized by a number of structures, including the articular congruence of the sigmoid fossa of the radius with the received

February 16, 2020

accepted

August 18, 2020
DOI https://doi.org/

$10.1055 / \mathrm{s}-0040-1719013$. ISSN 1698-8396.
Copyright $\odot 2020$ Thieme Revinter

Publicações Ltda, Rio de Janeiro, Brazil
License terms

(c) $(1) \$$ 
ulnar head, the TFCC, the pronator quadratus and extensor carpi ulnaris muscles, and the distal oblique bundle (DOB). The DOB has gained importance in recent years. It is a ligamentous reinforcement at the most distal portion of the interosseous membrane, present in $40 \%, 50 \%$ or even $70 \%$ of the population. It arises from the distal $1 / 6$ of the ulnar diaphysis, attaching itself to the lower dorsal edge of the sigmoid fossa of the radius; it influences DRUJ stability in all rotational positions of the forearm. Under normal circumstances, it is a secondary stabilizer of the DRUJ; however, when the TFCC is injured, it becomes an important joint stabilizer both in palmar and dorsal deviations. ${ }^{2}$ As such, in recent years, several techniques have been developed in an attempt to reconstruct this ligamentous reinforcement.

The present paper aims to describe a simple, reproducible technique for DOB reconstruction with an extensor carpi radialis longus (ECRL) hemitendon, increasing DRUJ stability.

\section{Surgical Technique and Clinical Cases}

The technique described is indicated in patients with DRUJ instability with irreparable TFCC or previously unsuccessful TFCC repair with no joint degeneration.

\section{Surgical Technique}

Ultrasonography was used before surgery to identify the distal level of the ECRL tendon and the myotendinous junction at the proximal level.

An arthroscopy was performed to confirm the presence of an irreparable TFCC rupture and the absence of degenerative lesions.

Under ischemia and with the forearm in prone position on the surgical table, an incision was performed at the dorsoradial aspect of the wrist at the level of the styloid process of the radius, where the ECRB was identified using ultrasound; next, dissection and reference (with a vessel loop) were performed. The tendon was marked between $3.5 \mathrm{~mm}$ and $4 \mathrm{~mm}$ on its radial side and divided with a \#11 scalpel, grasping the radial hemitendon with a wire loop.

Next, a new 2-cm incision was performed at the level of the proximal mark until the ECRL was opened at its myotendinous junction. A retriever (arthroscopic Grasper forceps) was introduced through this opening in an antegrade manner until it came out at the distal incision. The wire loop was retrieved and extracted through the proximal incision, and then pulled proximally to section the tendon longitudinally. The hemitendon was sectioned at the proximal level and recovered in its entire length, being pulled through a distal approach (-Figure 1a).

The next step was to perform a bone tunnel in the radius and in the distal third of the ulnar diaphysis according to the previous anatomical descriptions proposed in the literature. This procedure was aided by a specific percutaneous C-guide (Arthrex, Naples, Florida, US) and performed under fluoroscopic control. To calculate guide obliquity, a $50^{\circ}$ angle was measured with a goniometer to place the distal branch parallel to the distal epiphysis of the radius (-Figure $\mathbf{1 b}$ ). First, a 2.4-mm Kirschner wire was passed through the guide in an oblique direction from the radius styloid to the proximal limit of the radial sigmoid fossa, and it was drilled (with a 4-mm cannulated drill) until reaching the second cortical layer of the radius, avoiding iatrogenic injury to the interosseous membrane. The same process was performed at the ulna, passing a needle under fluoroscopic control, followed by drilling.

The hemitendonplasty was prepared with a 4/0 nonabsorbable braided suture, according to the Krakow technique, placed on its free end. The suture was performed from the radial to the ulnar tunnels with a passer (wire loop, suture lasso etc.), and pulled to recover the tendon end at the ulnar level.

The plasty was fixed at the levels of the radial and ulnar tunnels using a $4 \times 10-\mathrm{mm}$ biotenodesis screw with the forearm in $60^{\circ}$ of supination (-Figure 1c and 1d). Finally, the distal hemitendon was sectioned at its attachment to the radius, leaving the remaining tendon independent from the ECRL.

The wound was closed in planes and the arm was immobilized with a brachiopalmar splint in neutral prone supination for 4 weeks, followed by an antebrachial splint for another 2 weeks. Next, elbow flexion-extension exercises were started, avoiding prone supination. Full range of motion was allowed at 6 weeks. Strengthening exercises were restricted until the 12 th week, when joint balance was complete and there was no DRUJ instability.

\section{Clinical Cases}

We present two cases in which this surgical technique has been used.

The first case (28-year-old male, dominant right hand) was a polytraumatized patient who suffered a DRUJ dislocation that was diagnosed 4 weeks after admission (- Figure 2). Surgical reduction of the DRUJ was performed through a dorsal approach to the wrist. In this case, the DRUJ was shown to be unstable, with irreparable TFCC damage.

The second patient (42-year-old female, dominant right hand) had DRUJ instability at direct TFCC repair under arthroscopy (-Figure 3 ). The patient still presented pain, and the TFCC rupture was diagnosed on the same magnetic resonance imaging (MRI) scan. During the intervention, an irreparable Palmer type-Ib tear was observed.

Both patients were evaluated with more than 1 year of evolution (at 17 and 13 months respectively), with very satisfactory functional outcomes and a stable DRUJ in the entire range of motion. Patient 1 had a joint balance of $75^{\circ}$ in supination and $70^{\circ}$ in pronation, with full flexion-extension, whereas patient 2 presented $65^{\circ}$ in supination and $70^{\circ}$ in pronation, with full flexion-extension. The visual analog scale (VAS) score for pain was 1 in the first case and 2 in the second case. Both subjects returned to their usual activities.

\section{Discussion}

There are numerous indirect or direct radioulnar reconstruction techniques, and most of them can restrict forearm rotation. 


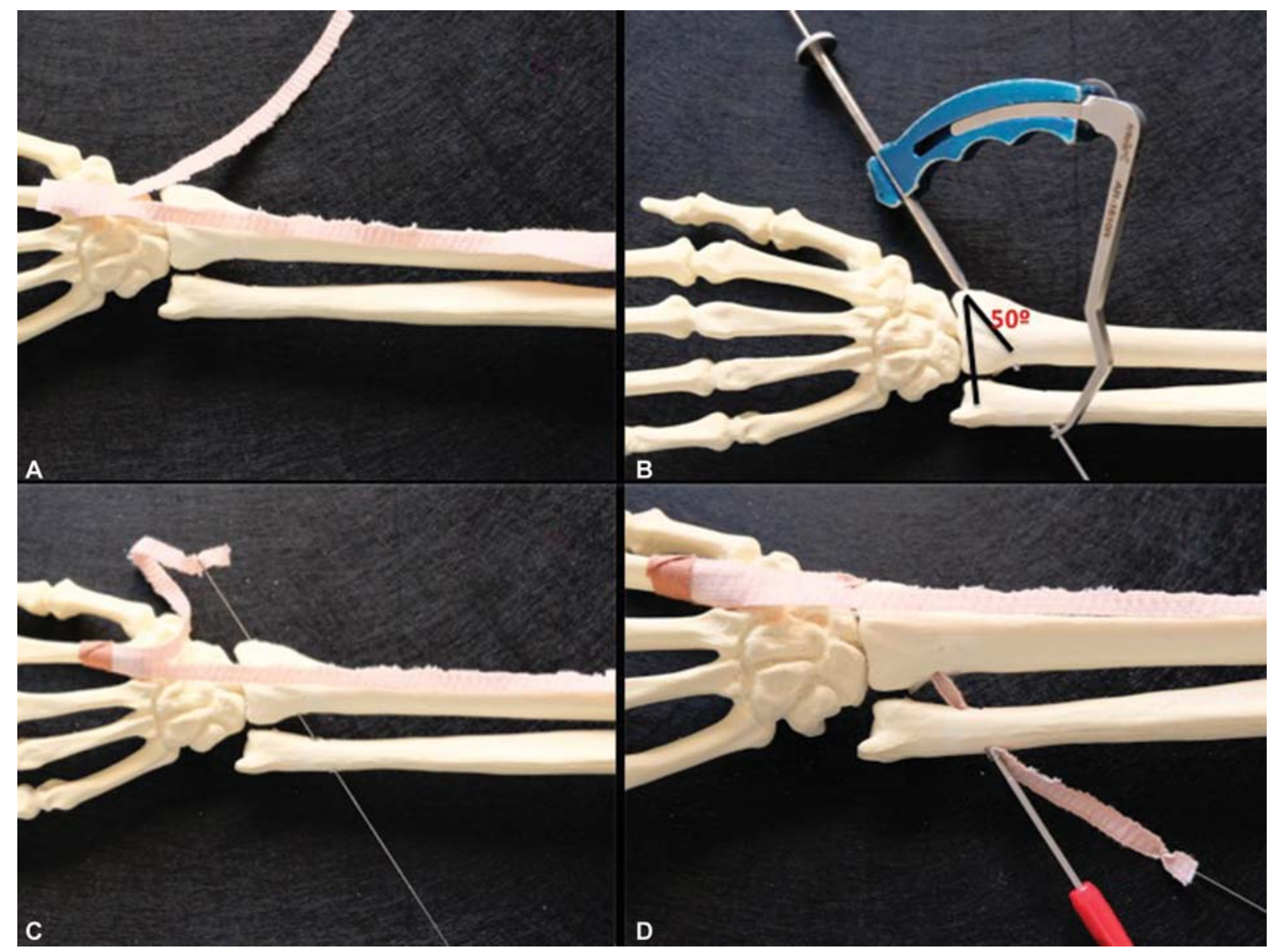

Fig. 1 Schematic representation of the technique. (A) Extensor carpi radialis longus (ECRL) hemitendon graft. (B) Bone tunnels drilled under percutaneous guidance. (C) ECRL hemitendon passing through the tunnels. (D) Plasty fixation with interference screws.

The DOB is inconsistent, being found in $40 \%$ of the population, and it influences DRUJ stability in all positions of forearm rotation. ${ }^{3}$ Its importance has been described in distal radial fractures with TFCC rupture, since it maintains DRUJ stability when the radial height is corrected and DOB tension accounts for DRUJ reduction. ${ }^{4}$ Due to its disposition, some authors considered it a secondary DRUJ stabilizer, with special importance when primary DRUJ stabilizers, such as the TFCC and the distal radioulnar ligaments, are injured. $^{5}$

Several DOB reconstruction techniques have been described recently. In 2013, Riggenbach et al. $^{6}$ performed an anatomical study in cadavers comparing the reconstruction of distal radioulnar ligaments and DOB reconstruction. The Adams technique was used for the reconstruction of the radioulnar ligaments, whereas the DOB was replaced with a palmaris longus or an extensor carpi radialis brevis (ECRB) hemitendon graft; both techniques achieved similar functional outcomes; in addition, DOB reconstruction had no better functional outcome when associated with a supplementary Adams technique. In 2015, the same authors published their first clinical cases of DOB reconstruction with satisfactory outcomes, tensioning the plasty in $60^{\circ}$ of supination and fixing it using a Pulvertaft suture. These patients were operated on with conventional approaches. We believe that arthroscopy or minimally-invasive surgery, such as the one we herein presented, must be used, since open procedures increase the risk of joint stiffness.

Brink and Hannemann ${ }^{7}$ published a reconstruction technique with radial and ulnar tunnels in the anatomical position of the DOB using the palmaris longus tendon or the hemitendon of the flexor carpis radialis and fixing it in maximum supination with an interferential biotenodesis screw, with good clinical outcomes in 14 subjects.

De Vries et al. ${ }^{8}$ published a study performed in cadavers of a minimally-invasive technique using a button-type suspension system (Tight-Rope, Arthrex) towards the DOB, with good DRUJ stability.

In our opinion, the use of a specific guide reduces the aggression to soft tissues and increases procedural reproducibility and safety. Our technique spares from injury neurovascular structures close to the interosseous membrane, the space of Parona or the volar components of the forearm. The use of the radial hemitendon of the ECRL can be a good alternative, with low morbidity for DOB reconstruction; it is easy to obtain and handle by tightening it before its distal tenotomy. It is indicated in cases of failure or impossibility of TFCC repair, to support a non-acute TFCC injury, and in wrist fractures with distal radioulnar instability after osteosynthesis. 


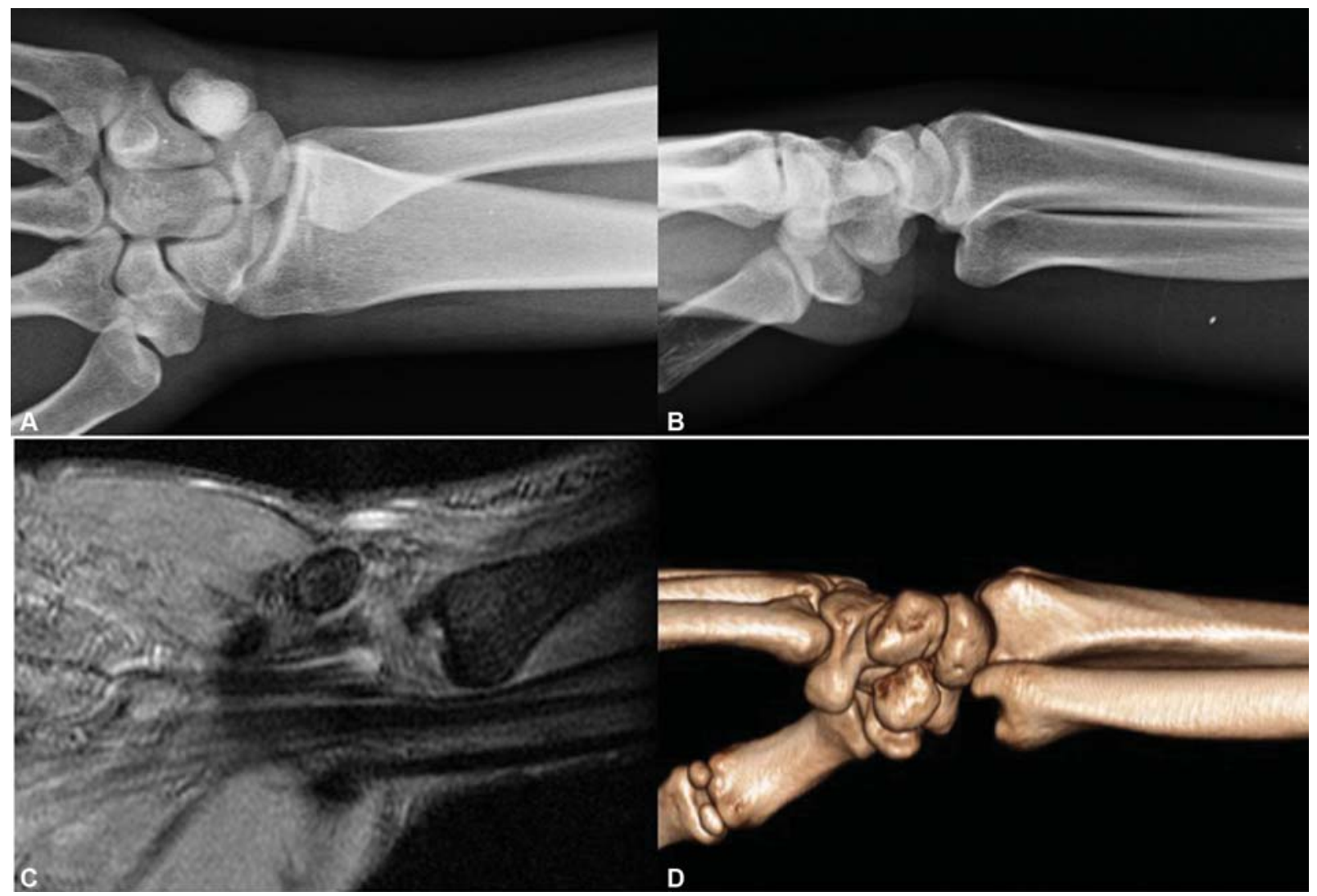

Fig. 2 Distal radioulnar luxation. (A-B) Volar dislocation of the ulnar head in anteroposterior and lateral radiographs. (C-D) Magnetic resonance imaging (MRI) and computed axial tomography (CAT) scans.

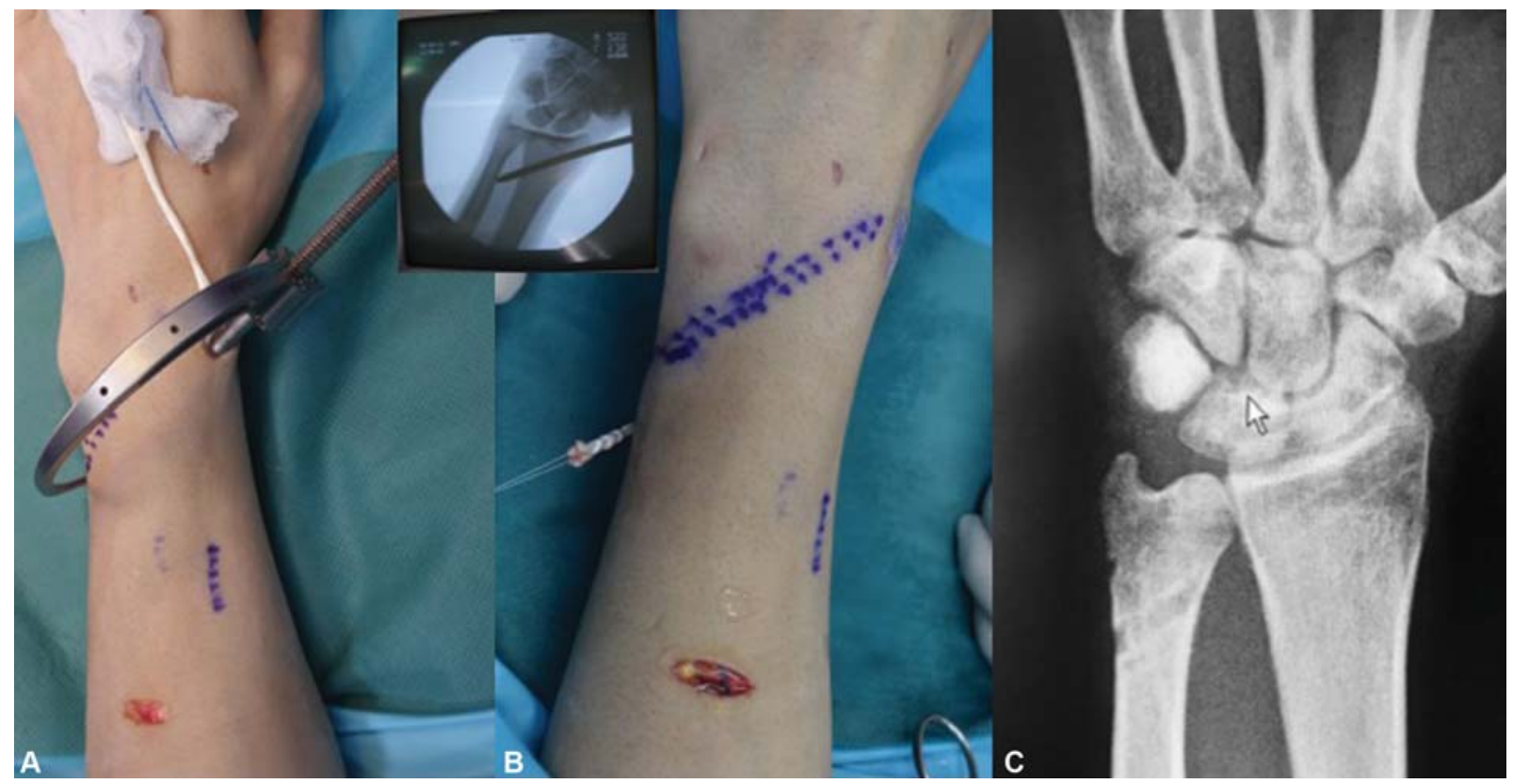

Fig. 3 Reconstruction of the distal oblique bundle. (A-B) Intraoperative images. (C) Postoperative radiograph.

Recently, articles such as the one by Low et al. ${ }^{9}$ reported similar outcomes from the reconstruction of radioulnar ligaments and of the DOB.

Due to its length, the tendon ${ }^{10}$ may be used in cases of longitudinal instability of the forearm, also repairing the middle oblique band of the interosseous membrane, in addition to the DOB.

\section{Conflict of Interests}

The authors have no conflict of interests to declare. 
142 Reconstruction of the Distal Oblique Bundle of the Interosseous Membrane Martínez-Martínez et al.

\section{References}

1 Kakar S, Carlsen BT, Moran SL, Berger RA. The management of chronic distal radioulnar instability. Hand Clin 2010;26(04): 517-528

2 Moritomo $\mathrm{H}$. The distal oblique bundle of the distal interosseous membrane of the forearm. J Wrist Surg 2013;2(01):93-94

3 Moritomo H, Noda K, Goto A, Murase T, Yoshikawa H, Sugamoto K. Interosseous membrane of the forearm: length change of ligaments during forearm rotation. J Hand Surg Am 2009;34(04): 685-691

4 Dy CJ, Jang E, Taylor SA, Meyers KN, Wolfe SW. The impact of coronal alignment on distal radioulnar joint stability following distal radius fracture. J Hand Surg Am 2014;39(07):1264-1272

5 Omokawa S, Iida A, Kawamura K, et al. A Biomechanical Perspective on Distal Radioulnar Joint Instability. J Wrist Surg 2017;6(02): 88-96
6 Riggenbach MD, Conrad BP, Wright TW, Dell PC. Distal oblique bundle reconstruction and distal radioulnar joint instability. J Wrist Surg 2013;2(04):330-336

7 Brink PRG, Hannemann PF. Distal oblique bundle reinforcement for treatment of DRUJ instability. J Wrist Surg 2015;4(03):221-228

8 de Vries EN, Walenkamp MM, Mulders MA, Dijkman CD, Strackee SD, Schep NW. Minimally invasive stabilization of the distal radioulnar joint: a cadaveric study. J Hand Surg Eur Vol 2017; 42(04):363-369

9 Low SL, Clippinger BB, Landfair GL, Criner-Woozley K. A Biomechanical Evaluation of the DRUJ after Distal Oblique Bundle Reconstruction. J Hand Surg Am 2020;45(05):452.e1-452.e8

10 Fahandezh-Saddi Diaz H. Estudio anatómico del abductor accesorio de la mano y su correlación clínico-ecográfica. Estudio en cadáver. (Tesis doctoral). Madrid: Departamento de cirugía, Universidad Complutense de Madrid; 2015 